\title{
Applying Recurrent Fuzzy Neural Network to Predict the Runoff of Srepok River
}

\author{
Hieu N. Duong ${ }^{1}$, Quyen N.T. Nguyen ${ }^{2}$, Long T. Bui ${ }^{3}$, Hien T. Nguyen ${ }^{4}$, Vaclav \\ Snasel ${ }^{5}$ \\ ${ }^{1}$ Faculty of Computer Science and Engineering, HCM University of Technology, Vietnam \\ ${ }^{2}$ Tay Nguyen University, Vietnam \\ ${ }^{3}$ Faculty of Environment and Natural Resources, HCM University of Technology, Vietnam \\ ${ }^{4}$ Faculty of Information Technology, Ton Duc Thang University, Vietnam \\ ${ }^{5}$ Department of Computer Science, VSB-Technical University of Ostrava, Czech Republic \\ dnhieudcse.hcmut.edu.vn, \\ ngocquyendhtn@yahoo.com.vn, longbt62@hcmut.edu.vn, \\ hien@tdt.edu.vn, vaclav.snasel@vsb.cz
}

\begin{abstract}
Recurrent fuzzy neural network (RFNN) is proven to be a great method for modeling, characterizing and predicting many kinds of nonlinear hydrological time series data such as rainfall, water quality, and river runoff. In our study, we employed RFNN to find out the correlation between the climate data and the runoff of Srepok River in Vietnam and then to model and predict the runoff of Srepok River in the current, as well as in the future. In order to prove the advantage of RFNN, we compare RFNN with an environmental model called SWAT on the same dataset. We conduct experiments using the climate data and the daily river's runoff data that have been collected in 22 years, ranging from 1900 to 2011. The experiment results show that the relative error of RFNN is about 0.35 and the relative error of SWAT is 0.44 . It means that RFNN outperforms SWAT. Moreover, the most important advantage of RFNN when comparing with SWAT is that RFNN does not need much data as SWAT does.
\end{abstract}

Keywords: Srepok, SWAT, Data Mining, RFNN, Runoff.

\section{Introduction}

The climate change is one of the greatest challenges for the mankind in the 21 st century, affecting seriously to production, life, environment, as well as other fields of people in the world in generally and Vietnam in particularly. Therefore, all most of countries over the world have set a high priority to accommodate to climate change in the national development plan. In recognizing the serious causes of climate change, the Vietnamese Prime Minister, on December 02, 2008, approved the national target program accommodating to climate change. Two in eight important missions of the program are (i) to consider how the climate change effects to production and civilian 
and (ii) to determine solutions to accommodate to the climate change. To meet the call for attention in finding solutions for this emerging problem, in this paper, we propose an approach to predict the runoff of Srepok River in Vietnam in the futute.

The Srepok River is located in the Central Highland of Vietnam. Its watershed has a plentiful lake system, districts evenly. Due to slope terrain, the water maintaining ability is not good and most of small streams of the river almost run out of water in the dry season and the water of several big lakes drop into a very low level. Together with the impact of climate change, the unusually change of the watershed of the Srepok River as observed recently has posed a challenging problem to water resource security of Vietnam. After monitoring the Srepok runoff in many years ranging from 1990 to 2011, we realize that the Srepok runoff has varied too strange that nobody can understand exactly what correct natural rules it holds, even for civilian. Naturally, the Srepok runoff varies with seasonal rule by year; it is low in dry season and high in wet season. But in a few years, the Srepok runoff decreases suddenly in dry season or increases suddenly in wet season and it is worth to warn because it impacts directly to people life in the Srepok basin. That raises the challenge is how to simulate and predict the Srepok runoff in order to help the managers and civilian adapt with its anomaly.

In the environment field, one often applies several kinds of environmental toolkit to model the impact of climate change to water resource, especially runoff of rivers. In [2] the authors used SWAT tool and Mike software to model the change of water resources and land resources. However, one of disadvantages of this method when adapting to the environments in Vietnam is that SWAT tool and Mike software require a lot kinds of data, ranging from climate, water resource to soil map data, but those of the environment and natural resources in Vietnam are not available.

In this paper, we propose a new method that applies data mining in order to model the correlation between the climate data and the Srepok runoff. And then the correlation is used to predict the Srepok runoff in the future. Among many effective models and algorithms available, we employ a hybrid of neural network and fuzzy theory to build a prediction toolkit. After developing the toolkit, we try to compare the result of two methods: SWAT and data mining. By the specific experiments, we conclude exactly the advantages of our approach and draw more researches for future work.

The rest of this paper is organized as follows. Section 2 presents the related work. Section 3 presents the dataset used in experiments. Section 4 introduces recurrent fuzzy neural network. In section 5, we present experiments. Some finding will be pointed out in Section 5. Finally, we draw conclusion and perspectives for future work.

\section{Related work}

In this section, we present related work on river runoff predicting and especially employing artificial neural network. The authors in [8] identify the impact of climate change to hydrology of the Upper Nile River. They showed assessment of changes in water resources and the impacts of dam operation. The study was conducted with the 
hydrological data that are limited and therefore use the simple, reliable method, and simulate the impact of different change climate scenarios on hydrology and water resources in the river basin.

In 2007, Ibrahim Can [9] applied two different kinds of artificial neural network that are the feed forward neural network back propagation (FFBP) and Generalized Regression Neural Network (GRNN) in order to predict the Karasu River runoff. Besides, in 2009, a study of Lance E. Besaw et al. [10] also demonstrated the use of neural networks was effective for predicting driver runoff. Lance E. Besaw et al. pointed out that predictions based on hourly data more efficiently than using daily data because important relationships between climate and the runoff was lost as predicting by day. Also in other studies, Lekkas DF [11] confirmed a multilayer backpropagation network with almost all components used for hydrological applications. Also using neural networks for predicting, Saman Razavi et al [13] and Alireza Mardookhpour [14] confirmed neural network more effective than traditional methods. Neural networks are widely used for hydrologic prediction problem and were gradually replaced by the traditional prediction model, such as models of Transfer Function (TF) in the study by Demetris F. Lekkas [15].

In Viet Nam, 2007 Pham Thi Hoang Nhung, Quang Thuy Ha [3] studied how to use artificial neural network in predicting of the Hoa Binh runoff before 10 days. The authors analyzed artificial neural network to predict the runoff and applied genetic algorithm for learning neural network. Nguyen Thanh Son et al. [4] studied the effect of climate change to water resources of Nhue River basin. In the study the authors also indicated other methodologies as climate change scenarios or NAM models to study how important climate change is. They conducted the simulations of the climate change effects on water resources and had much valuable assessment.

Tran Thanh Xuan [5] studied the impacts of climate change on river runoff in and pointed out the factors that influence most to the river runoff. In [7], the author researched applications of artificial neural networks to predict rainfall and river runoff to prevent and restrict drought of the river basins in the Central Highland of Vietnam. In the study, the model proved very effective on predicting river runoff.

\section{Data set}

In the Central Highland of Vietnam, there are several climate stations that gather automatically climate data. For our research, we gather 22 years data from 1990-2011 of the Srepok River. The data was collected daily. We stored the data collected each day in a record, each of which consists of nine fields capturing information of that day as follows: average of temperature, maximum of temperature, minimum of temperature, average of humid degree, minimum of humid degree, rain quantity, evaporation per day, the number of sunning hours, and runoff. In total we collected 7665 records.

After gathering and analyzing the Srepok runoff data and the climate data, we realize that are kinds of time series data and there are some hidden correlations between them. But, if we just only employ a few normal visualizing techniques to find out the correlation, it is hard to monitor by the analyzer. As a result, it also is difficult to con- 
clude what happens with the Srepok runoff in the future when the climate is going to change little but continuously by time. So we propose a new method that employs data mining techniques to discover this correlation.

\section{Proposed method}

There are many methods that can be used for predicting the time series data like the Srepok runoff data with accepted accuracy. We can use any regression methods to solve the issue such as linear regression, nonlinear regression, fuzzy system, artificial neural network, support vector machine, etc. Every method has some advantages and also disadvantages depending on the data with specific characteristics. However, it is not easy to state which method is better than other and the appropriate answer for the most suitable chosen method comes from analysis of experiment results. After evaluating the historical data of the Srepok runoff and the climate data we decided to employ a hybrid of artificial neural network and fuzzy system called recurrent fuzzy neural network (RFNN). RFNN works more effective than standard neural network $[1,6]$ when we compare these at two criterions (i) RFNN can estimate more complex relationship between dependent and independent variables and (ii) the convergence of RFNN is faster than standard neural network. Structure of RFNN is shown as Fig 1 and RFNN includes four layers as follows:

- Layer 1 is input layer that has $N$ nodes, each of which corresponds with a parameter. In our data, input could be all parameters of the climate data.

- Layer 2 is called membership layer. Nodes in this layers will convert the crisp data in fuzzy data by applying membership functions such as Gauss function. Number of neural nodes in this layer is $N x M$ where $M$ is the number of fuzzy rules.

- Layer 3 is the layer of fuzzy rules. Each node in this layer plays the role of a fuzzy rule. Connecting between Layer 3 and Layer 4 presents for fuzzy conclusion.

- Layer 4 is the output layer including $P$ nodes. In our model, $P$ will be set to one and this is the driver runoff value. 


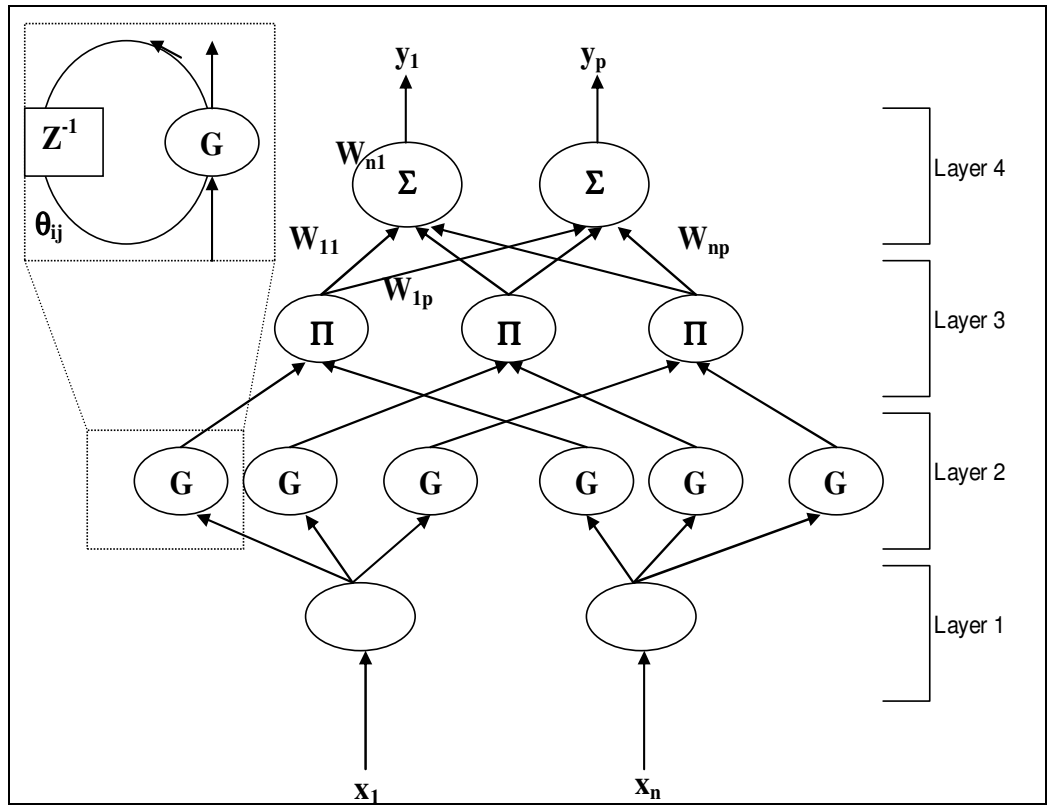

Fig. 1. $R$ FNN Architecture

\section{Model process}

We employ a popular algorithm that learns parameters $m_{i j}, \sigma_{i j}, \theta_{i j}$ and $w_{j k}$ respectively. Let $u_{i}^{(k)}$ and $O_{i}^{(k)}$ be respectively the input and the output of the node $\mathrm{i}^{\text {th }}$ in the layer $\mathrm{k}$.

- Layer 1: $O_{i}^{(1)}=u_{i}^{(1)}=x_{i}(t) \quad i=1 \div N$

- Layer 2: note that every node has 3 parameters, namely $m_{i j}, \sigma_{i j}$ and $\theta_{i j}$ respectively.

$$
O_{i j}^{(2)}=\exp \left[-\frac{\left(u_{i j}^{(2)}-m_{i j}\right)^{2}}{\left(\sigma_{i j}\right)}\right] \quad \text { (1) } i=1 \div N, j=1 \div M, m_{i j} \text { and } \sigma_{i j} \text { are the center }
$$
and the variance of Gauss distribution function.

$$
u_{i j}^{(2)}(t)=O_{i}^{(1)}+\theta_{i j} O_{i j}^{(2)}(t-1) \quad \text { (2) } i=1 \div N, j=1 \div M, \theta_{i j} \text { denotes the weight of a }
$$
recurrent node.

We easily realize that the input of the nodes in this layer has the factor $O_{i j}^{(2)}(t-1)$. This factor denotes the remaining information of the previous model. Therefore, after replacing $u_{i j}^{(2)}$ in (1) by (2), we get equation (3) as follows: 


$$
\begin{aligned}
O_{i j}^{(2)} & =\exp \left[-\frac{\left[O_{i}^{(1)}+\theta_{i j} O_{i j}^{(2)}(t-1)-m_{i j}\right]^{2}}{\left(\sigma_{i j}\right)^{2}}\right] \quad i=1 \div N, j=1 \div M \\
& =\exp \left[-\frac{\left[x_{i}(t)+\theta_{i j} O_{i j}^{(2)}(t-1)-m_{i j}\right]^{2}}{\left(\sigma_{i j}\right)^{2}}\right]
\end{aligned}
$$

- Layer 3: Each node in this layer corresponds with an AND expression. Each AND expression is defined as follows:

$$
O_{j}^{(3)} \quad=\prod_{i=1}^{N} O_{i j}^{(2)}=\prod_{i=1}^{N} \exp \left[-\frac{\left[x_{i}(t)+\theta_{i j} O_{i j}^{(2)}(t-1)-m_{i j}\right]^{2}}{\left(\sigma_{i j}\right)^{2}}\right] \text { where } j=1 \div M
$$

- Layer 4: Nodes of this layer are responsible for converting fuzzy to crisp.

$$
\begin{aligned}
y_{k} \quad=O_{k}^{(4)}=\sum_{j=1}^{M} u_{j k}^{(4)} w_{j k} \quad=\sum_{j=1}^{M} O_{j}^{(3)} w_{j k} \\
=\sum_{j=1}^{M} w_{j k} \prod_{i=1}^{N} \exp \left[-\frac{\left[x_{i}(t)+\theta_{i j} O_{i j}^{(2)}(t-1)-m_{i j}\right]^{2}}{\left(\sigma_{i j}\right)^{2}}\right] \quad \text { where } k=1 \div P
\end{aligned}
$$

After defining RFNN architecture, RFNN is learnt by back propagation algorithm. Each learning step spends much time to learn $85 \%$ of all data (18 years data). Then RFNN will be tested in $15 \%$ data and evaluated. If it gives prediction results correct, the learning step will be stopped; otherwise the learning is continuous.

\section{Learning algorithm}

Back propagation algorithm is applied for learning RFNN that is the same with feed forward neural network (FFNN). The target of the applied algorithm is how to minimize the sum square error (SSE):

$$
E=\frac{1}{2} \sum_{t}\left(y^{(d)}(t)-y(t)\right)^{2}=\frac{1}{2} \sum_{t}\left(y^{(d)}(t)-O^{(4)}(t)\right)^{2} \text {, in which } y^{(d)}(t) \text { is the }
$$

real river runoff and $y(t)=O^{(4)}(t)$ is the calculated river runoff from RFNN at the $t^{\text {th }}$ tuple. In back propagation algorithm, the parameters are updated as follows:

$$
W(t+1)=W(t)+\Delta W(t)=W(t)+\eta\left(-\frac{\partial E(t)}{\partial W}\right), \text { in which } W \text { is a parameter vector }
$$

of the model and $\eta$ is the learning rate.

Let $e(t)=y^{(d)}(t)-y(t)$, we have: $\frac{\partial E(t)}{\partial W}=-e(t) \frac{\partial y(t)}{\partial W}=-e(t) \frac{\partial O^{(4)}(t)}{\partial W}$

Therefore, $m_{i j}, \sigma_{i j}, \theta_{i j}$ and $w_{j k}$ will be updated as:

$$
\begin{aligned}
& w_{j k}(t+1)=w_{j k}(t)-\eta^{w} \frac{\partial E}{\partial w_{j k}} ; m_{i j}(t+1)=m_{i j}(t)-\eta^{m} \frac{\partial E}{\partial m_{i j}} \\
& \sigma_{i j}(t+1)=\sigma_{i j}(t)-\eta^{\sigma} \frac{\partial E}{\partial \sigma_{i j}} \quad ; \theta_{i j}(t+1)=\theta_{i j}(t)-\eta^{\theta} \frac{\partial E}{\partial \theta_{i j}}, \text { in which }
\end{aligned}
$$




$$
\begin{aligned}
\frac{\partial E}{\partial w_{j k}}=-e(t) O_{j}^{(3)} & \frac{\partial E}{\partial m_{i j}} \quad=-e(t) \sum_{j=1}^{M} w_{j k} \frac{\partial O_{j}^{(3)}}{\partial m_{i j}} \\
& =-e(t) \sum_{j=1}^{M} w_{j k} O_{j}^{(3)} \frac{2\left[x_{i}(t)+O_{i j}^{(2)}(t-1) \theta_{i j}-m_{i j}\right]}{\left(\sigma_{i j}\right)^{2}} \\
\frac{\partial E}{\partial \sigma_{i j}} \quad & =-e(t) \sum_{j=1}^{M} w_{j k} \frac{\partial O_{j}^{(3)}}{\partial \sigma_{i j}} \\
& =-e(t) \sum_{j=1}^{M} w_{j k} O_{j}^{(3)} \frac{2\left[x_{i}(t)+O_{i j}^{(2)}(t-1) \theta_{i j}-m_{i j}\right]^{2}}{\left(\sigma_{i j}\right)^{3}} \\
\frac{\partial E}{\partial \theta_{i j}} & =-e(t) \sum_{j=1}^{M} w_{j k} \frac{\partial O_{j}^{(3)}}{\partial \theta_{i j}} \\
& -e(t) \sum_{j=1}^{M} w_{j k} \frac{-2\left[x_{i}(t)+O_{i j}^{(2)}(t-1) \theta_{i j}-m_{i j}\right] O_{i j}^{(2)}(t-1)}{\left(\sigma_{i j}\right)^{2}}
\end{aligned}
$$

In summary, our learning model is a supervised learning model with $\mathrm{t}^{\text {th }}$ tuple $\left\{\left(\mathrm{X}_{\mathrm{t}}, \mathrm{y}_{\mathrm{t}}\right)\right\} . \mathrm{X}_{\mathrm{t}}=\left(\mathrm{x}_{1}, \mathrm{x}_{2}, \ldots, \mathrm{x}_{\mathrm{n}}\right)$ is a vector of the climate data and $\mathrm{y}_{\mathrm{t}}$ is its corresponding the Srepok runoff at the same time. The work flow will be executed as follows:

- Step 1: Feed forward $X_{t}$ through RFFN to get output as:

$$
y_{k} \quad=\sum_{j=1}^{M} w_{j k} \prod_{i=1}^{N} \exp \left[-\frac{\left[x_{i}(t)+\theta_{i j} O_{i j}^{(2)}(t-1)-m_{i j}\right]^{2}}{\left(\sigma_{i j}\right)^{2}}\right]
$$

- Step 2: Calculating error between the real value and output of RFNN for $\mathrm{s}^{\text {th }}$ tuple. Let $e(t)$ be the error value and $e(t)=y_{k}(t)-y(t)$, in which $y_{k}(t)$ denotes the output value of RFNN and $y(t)$ denotes the real value.

- Step 3: Updating $m_{i j}, \sigma_{i j}, \theta_{i j}$ and $w_{j k}$ as the following expression:

$$
\begin{array}{ll}
w_{j k}(t+1)=w_{j k}(t)-\eta^{w} \frac{\partial E}{\partial w_{j k}} & ; m_{i j}(t+1)=m_{i j}(t)-\eta^{m} \frac{\partial E}{\partial m_{i j}} \\
\sigma_{i j}(t+1)=\sigma_{i j}(t)-\eta^{\sigma} \frac{\partial E}{\partial \sigma_{i j}} & ; \theta_{i j}(t+1)=\theta_{i j}(t)-\eta^{\theta} \frac{\partial E}{\partial \theta_{i j}}
\end{array}
$$

\section{Improving learning efficiency with momentum technique}

There is a popular technique that can help the RFNN learning overcome local minima and speed up the RFNN learning: it is momentum technique. When applying the technique, updating of $m_{i j}, \sigma_{i j}, \theta_{i j}$ and $w_{j k}$ are as the following expression:

$$
\begin{aligned}
& w_{j k}(t+1)=w_{j k}(t)-\eta^{w} \frac{\partial E}{\partial w_{j k}}+\beta \times \Delta w_{j k}(t-1) \\
& m_{i j}(t+1)=m_{i j}(t)-\eta^{m} \frac{\partial E}{\partial m_{i j}}+\beta \times \Delta m_{j k}(t-1)
\end{aligned}
$$




$$
\begin{aligned}
& \sigma_{i j}(t+1)=\sigma_{i j}(t)-\eta^{\sigma} \frac{\partial E}{\partial \sigma_{i j}}+\beta \times \Delta \sigma_{j k}(t-1) \\
& \theta_{i j}(t+1)=\theta_{i j}(t)-\eta^{\theta} \frac{\partial E}{\partial \theta_{i j}}+\beta \times \Delta \theta_{j k}(t-1)
\end{aligned}
$$

where $\beta$ is momentum term.

\section{Experiment}

\subsection{Experiments with SWAT Model}

SWAT is a hydrologic quality model developed by United States Department of Agricultural-Agricultural Research Service (USDA-ARS). It is a continuous time model that operates on daily time duration. The objective of model is to predict the impact of management on water, sediment, agricultural chemical yields in a large basin. SWAT is regression model that simulates the relationship between input parameters and predicted parameters. For predicting river runoff, the input parameters are much complex including several major hydrology components such as: weather, erosion map, sedimentation map, soil temperature, plant map, pesticide use, etc [16]. SWAT model uses Nash - Sutcliffe Index (NSI) value and coefficient of determination $\left(\mathrm{R}^{2}\right)$ to assess the quality of simulating model. The simulating quality of model is assessed with four levels: $0.9 \leq \mathrm{NSI} \leq 1$ : good; $0.7 \leq \mathrm{NSI} \leq 0.9$ : quite; $0.5 \leq \mathrm{NSI} \leq 0.7$ : mean; $0.3 \leq$ $\mathrm{NSI} \leq 0.5$ : weak.

As mentioning before, the input data is very important when applying SWAT to simulate river runoff. First of all, we must gather the input data of the Srepok runoff and the climate. Then, the input data are arranged with several different detail levels: 1) basin, sub-basin; 2) Hydrologic Response Units (HRUs); 3) space data: DEM, soil map, land use map; 4) climate data: max temperature, min temperature, rainfall, etc. Next, we process input data such as: land use map, soil map, topography, climatic conditions, etc that can be edited by ArcGis software. After that, SWAT model is applied to assess the impact of land use to the river runoff. In the end, we determine the relevant SWAT model to simulate the Srepok runoff.

Table 1. SWAT sensitive parameters and calibrated values

\begin{tabular}{|l|l|c|c|c|}
\hline \multirow{2}{*}{ Parameter } & \multirow{2}{*}{ Description of parameter } & \multicolumn{3}{|l|}{ Calibrated value } \\
\cline { 3 - 5 } & & Fitted value & Min value & Max value \\
\hline CN2. & Initial SCS CN II value & -0.17 & -0.20 & 0.20 \\
\hline ALPHA_BF & Base Flow Alpha factor & 0.17 & 0.00 & 1.00 \\
\hline GW_DELAY & Groundwater delay & 160.20 & 30.00 & 450.00 \\
\hline GWQMN & $\begin{array}{l}\text { Threshold water depth in the shallow } \\
\text { aquifer for flow }\end{array}$ & 1.26 & 0.00 & 2.00 \\
\hline
\end{tabular}


Table 2. Model performance for the simulation of flow-out

\begin{tabular}{|l|c|c|c|}
\hline \multirow{2}{*}{ Period } & \multirow{2}{*}{ Time step } & \multicolumn{2}{|c|}{ Value } \\
\cline { 3 - 4 } & & $\mathrm{R}^{2}$ & NSI \\
\hline Before calibration & Monthly & 0.70 & 0.41 \\
\hline Calibration (2004-2008) & Monthly & 0.75 & 0.68 \\
\hline Validation (2009-2011) & & 0.82 & 0.77 \\
\hline
\end{tabular}

After simulating the Srepok runoff at a hydrological station called Buon Don, we carry out the calibration and validation of the model. Four parameters are chosen to calibrate the model including Curve Number (CN2), Base flow Alpha factor (ALPHA_BF), Groundwater Delay (GW_DELAY), Threshold water depth in the shallow aquifer for flow (GWQMN). The calibration result is shown in Table 1. After that, we use calibrated result to run SWAT model again. Following that, we get the new values of NSI and $\mathrm{R}^{2}$ that are higher than the first times. Table 2 shows the calibration of SWAT model in 2004-2008. The fit of the simulated and observed runoff is acceptable because NSI is 0.68 and $R^{2}$ is 0.75 . Finally, we use the parameters found out from calibration to validate the model. In the result, the NSI value reached 0.77 and $\mathrm{R}^{2}$ was 0.82 and in Fig 2 compares the different between the simulated and observed runoff in 2009-2011. Therefore, this study can state that SWAT model is suitable to simulate the Srepok river runoff.

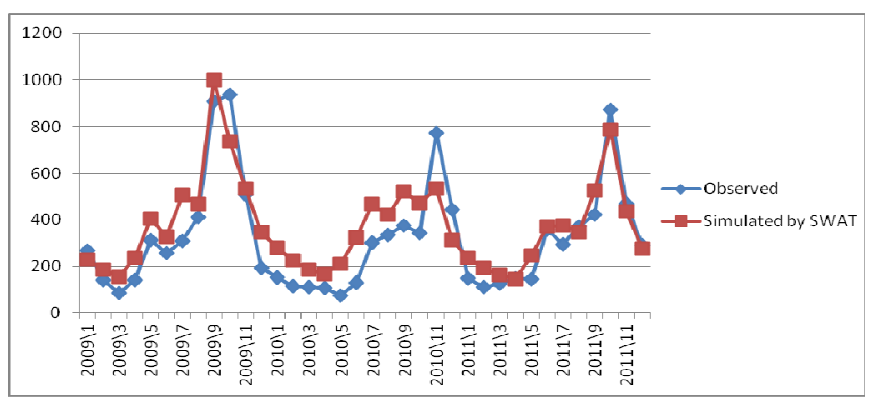

Fig. 2. Observed and simulated river runoff after validation

As mentioned-above, one of disadvantage of SWAT model is that SWAT must be provided enough and much data. Due to the lack of data, especially soil map data, in the current, we just only able to model the Srepok runoff to 2011. If provided enough and exactly input data, SWAT is potential to solve completely the raising problem.

\subsection{Experiments with RFNN}

In contrast with SWAT model, RFNN does not require much data but it has another disadvantage; RFNN is a black box for the analyzer. As mentioning in Section 4, in order to learn RFNN, the analyzer must input many parameters such as: learning rate, momentum, number of fuzzy rules. Unfortunately, it is hard to choose the relevant value for the parameters even the analyzer is an expert of RFNN researching. So for 
our experiment, we tried with several combinations of the parameters value and ran the algorithm 50 times, we found 5 combinations that give quite good result.

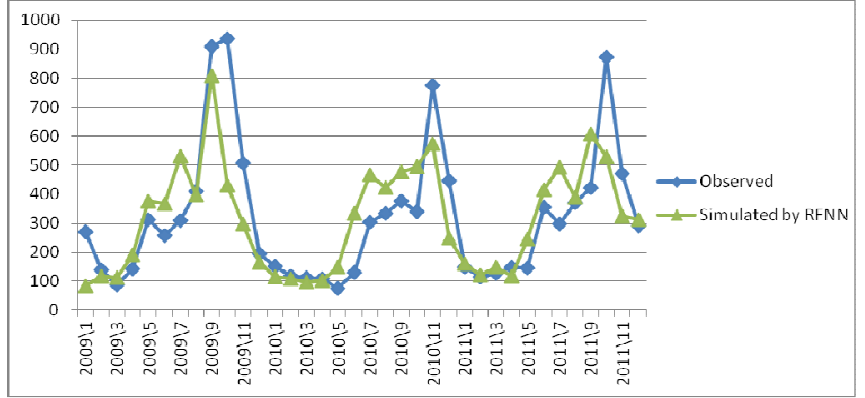

Fig. 3. Observed and simulated runoff with RFNN

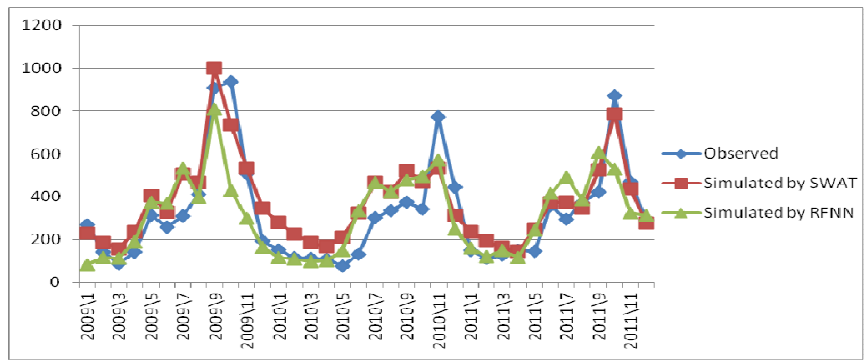

Fig. 4. Comparing observed, simulated runoff by SWAT and RFNN

In Fig. 3 shows the simulated runoff by RFNN when we set the number of fuzzy rules is 10 , learning rate is 0.001 , momentum is 0.001 and epoch number is 200,000 . We also use the data of Buon Don Station in 1900-2008 for learning and in 20092011 for testing. Fig. 4 compares the observed data with the simulated data modeling by SWAT and RFNN while Fig. 5 shows the relative error of two models. The relative error of RFNN is about 0.35 and if comparing with the relative error of SWAT is 0.44 , we can see that RFNN outperforms SWAT. However, it is superficial and incorrect if concluding that RFNN is better than SWAT. If we assess the mathematical property of two models, both are regression models. SWAT is hydrological model based on data of climate, soil, and water resource, so if we have enough and exact data, SWAT will simulate the river runoff better RFNN even the analyzer can find the optimal parameters for RFNN. In our case, we would like to confirm again our problem is that we cannot gather enough data for SWAT model not only in the future but also in the current. As a result, the raising problem is how to predict the Srepok runoff is impossible if using SWAT, but with RFNN, it is possible. Fig. 6 shows the results of prediction in 2015-2018 with the previous RFNN model. In this case, the climate data is gotten from SEA-START ${ }^{1}$.

1 http://startcc.iwlearn.org 


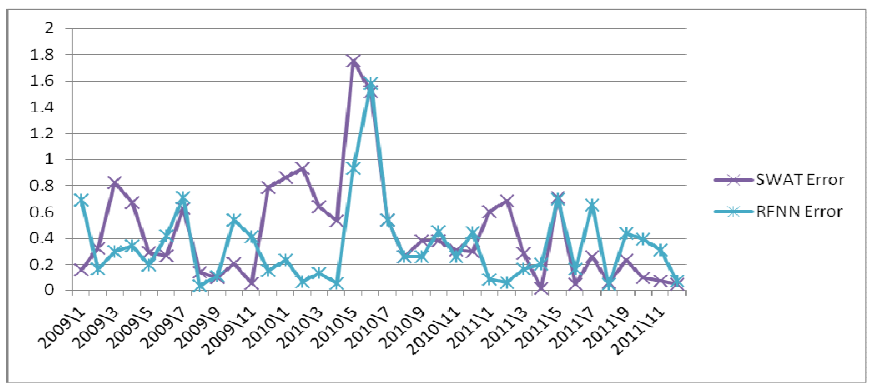

Fig. 5. Comparing related error between SWAT and RFNN

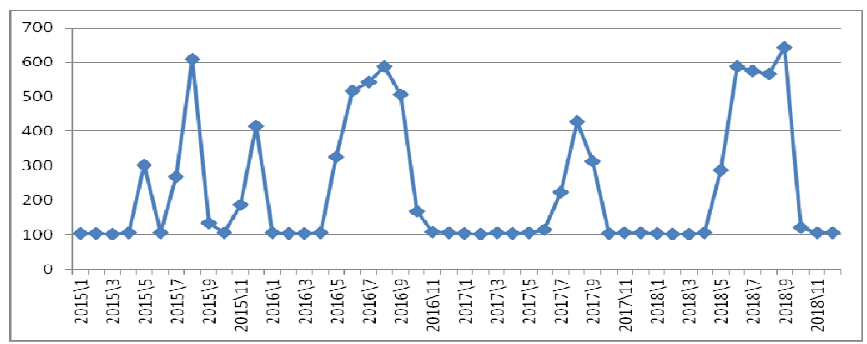

Fig. 6. The Srepok river runoff in 2015-2018 predited by RFNN

\section{Conclusions}

In this paper, we would like to introduce a new approach to simulate how climate changes influence to the Srepok runoff in Vietnam. Vietnam is an agricultural country, so water resources play a very important role in people life. Therefore, if the approach model can produce exactly data of the Srepok runoff in future, it will be so helpful for the national managers and the civilian. As mentioning in the experiment part, RFNN can predict quite exactly when comparing with the real data and the simulated data of SWAT model because the relative error of RFNN is quite low. Moreover, in Vietnam scenario, the most important advantage of RFNN when comparing with SWAT is that RFNN does not need much data as SWAT does. After analyzing the Srepok runoff we realize the data has seasonal varying. Therefore, in further research, we will try to highlight our time series data by applying chaos theory before employing RFNN.

\section{References}

1. Duong, H.N., Tran, Q.M., Dang, K.T.: Extendable Library of Basic Data Mining Algorithms. In: Proc. of the 11st Conference on Science \& Technology, Ho Chi Minh City University of Technology, (2009). 
2. Nguyen, Q.T.N., Bui L.T, Duong, H.N.: Assessment the impacts of land use and climate change on water discharge of Srepok river watershed. In: Proc. of the 34th Asian Conference on Remote Sensing, 152-164 (2013).

3. Pham N.T.H, Ha H.T.: How to apply artificial neural network for predicting warter level of Hoa Binh Lake before 10 days. In: Proc of the 10th Conference of Selected Issues in Communication and Information Technology, (2007).

4. Nguyen S.T., Ngo C.T, Van H.T, Nguyen, N.Y.: Impact of climate change on water resource of NHUE River basin. In: $27^{\text {th }}$ HaNoi National University Magazine of Science, 218-226 (2011).

5. Tran X.T., Hoang T.M., Le, N.T., Luong, D.H.: Impact of climate change on river runoff. In: $8^{\text {th }}$ Magazine of Science Presentation Selection, 146 - 153 (2011).

6. Duong, H.N.: Using RFNN to Predict Price of Products in Market". In: Proc. of the 9st Conference on Science \& Technology, HCM University of Technology, (2006).

7. Nguyen T. D.: Applying artificial neural network to predict rainfall and runoff to prevent and restrict drought in Viet Nam High Land basin rivers. In: Journal of Science and Engineering of Water Resource and Environment, 22 (2008).

8. Kim U., Kaluarachchi J. J., Smakhtin V. U.: Climate Change Impacts on Hydrology and Water Resources of the Upper Blue Nile River Basin, Ethiopia. In: IWMI Research Report, 126 (2008).

9. Can I., Yerdelen C., Kahya1, E. (2007), Stochastic modeling of Karasu River (Turkey) using the methods of Artificial Neural Networks, In: Proc. of the AGU Hydrology Days, 138-144 (2007).

10. Besaw, L. E., Rizzo, D. M., Bierman, P. R., Hackett, W. R.: Advances in ungauged stream flow prediction using artificial neural networks. In: Journal of Hydrology, 386, 27-37 (2010).

11. Lekkas D.F., Onof C.: Improved flow forecasting using artificial neural networks. In: Proc. of 9th International Conference on Environmental and Technology, 877-884 (2005).

12. Nazif, S., Karamouz, M., and Zahmatkesh, Z.: Climate Change Impacts on Runoff Evaluation: A Case Study. In: World Environmental and Water Resources Congress 2012, 33503360 (2012).

13. Razavi S., Araghinejad S.: Reservoir Inflow Modeling Using Temporal Neural Networks with Forgetting Factor Approach, Water Resour Manage. In: International Journal of Water Resource Management, 23, 39-55 (2009).

14. Mardookhpour A.: Prediction of stream flow by utilizing artificial neural network in floodplain (Case study: Sepidroud watershed). In: International Journal of Forest, Soil and Erosion, (2013).

15. Lekkas D.F.: Development and Comparison of Data-Based Flow Forecasting Methods. $\mathrm{PhD}$ Thesis, Department of Civil and Environmental Engineering. Imperial College of Science, Technology and Medicine, (2002).

16. Santhi, C., Arnold, J. G., Williams, J. R., Dugas, W. A., Srinivasan, R., Hauck, L. M.: Validation of the SWAT model on the large river basin with point and nonpoint sources. In: Journal of American water resources association, 37, 1169-1188 (2001).

17. Shudong, Z., Weiguang, L., Jun, N., Guangzhi, W., Lina, Z.: Combined Method of Chaotic Theory and Neural Networks for Quality Prediction. In: Journal of Northeast Agricultural University, 17, 71-76 (2010). 